
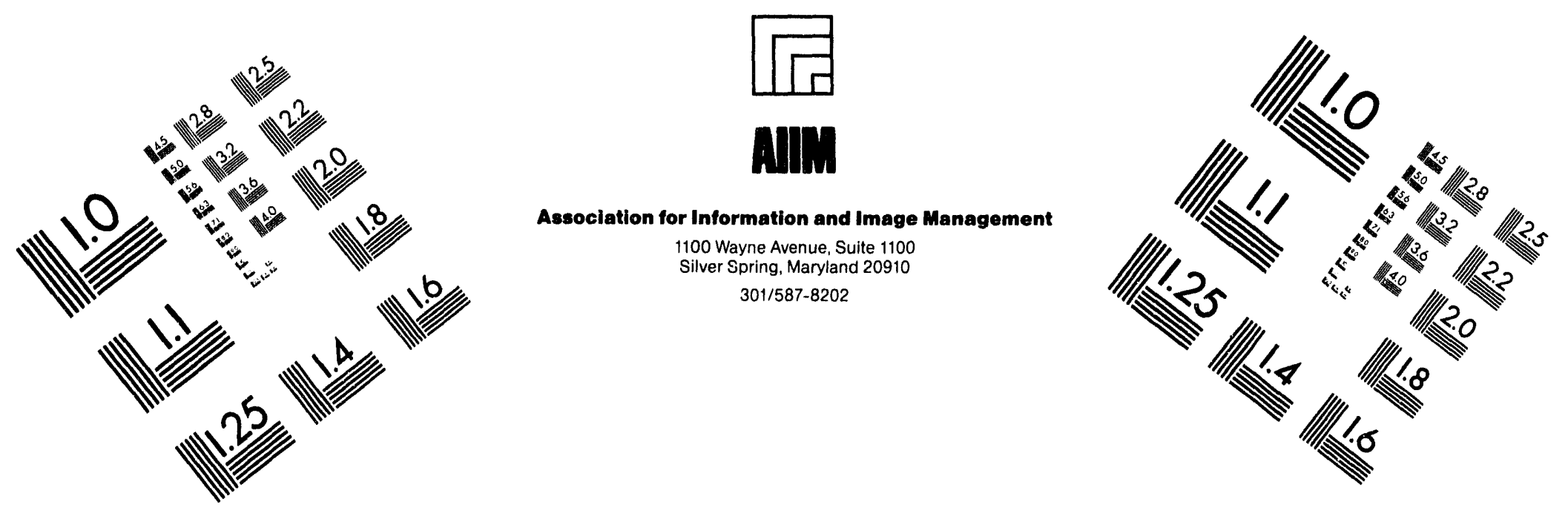

\title{
Centimeter
}

$\begin{array}{lllllllllllllll}1 & 2 & 3 & 4 & 5 & 6 & 7 & 8 & 9 & 10 & 11 & 12 & 13 & 14 & 15 \\ \mathrm{~mm}\end{array}$ | Inches

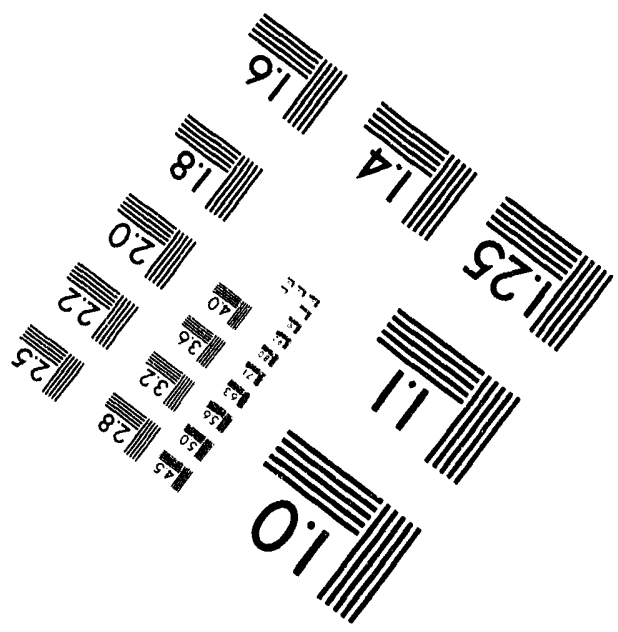

MANUFACTURED TO AIIM STANDARDS BY APPLIED IMAGE, INC.

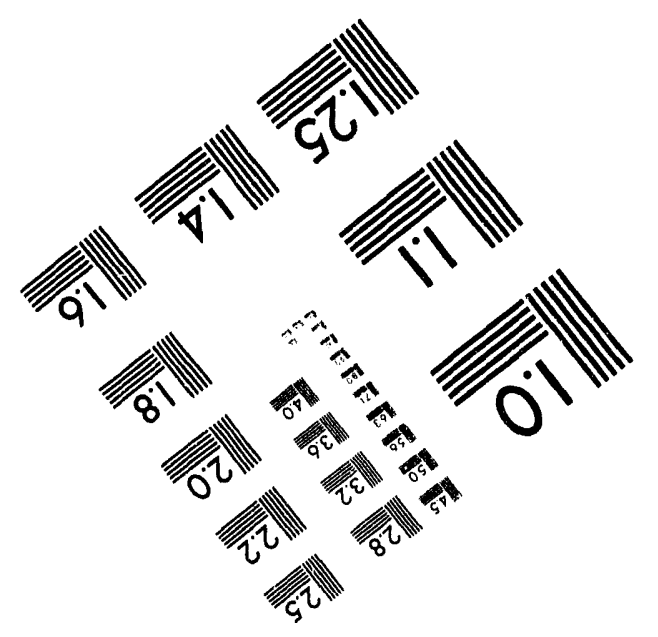



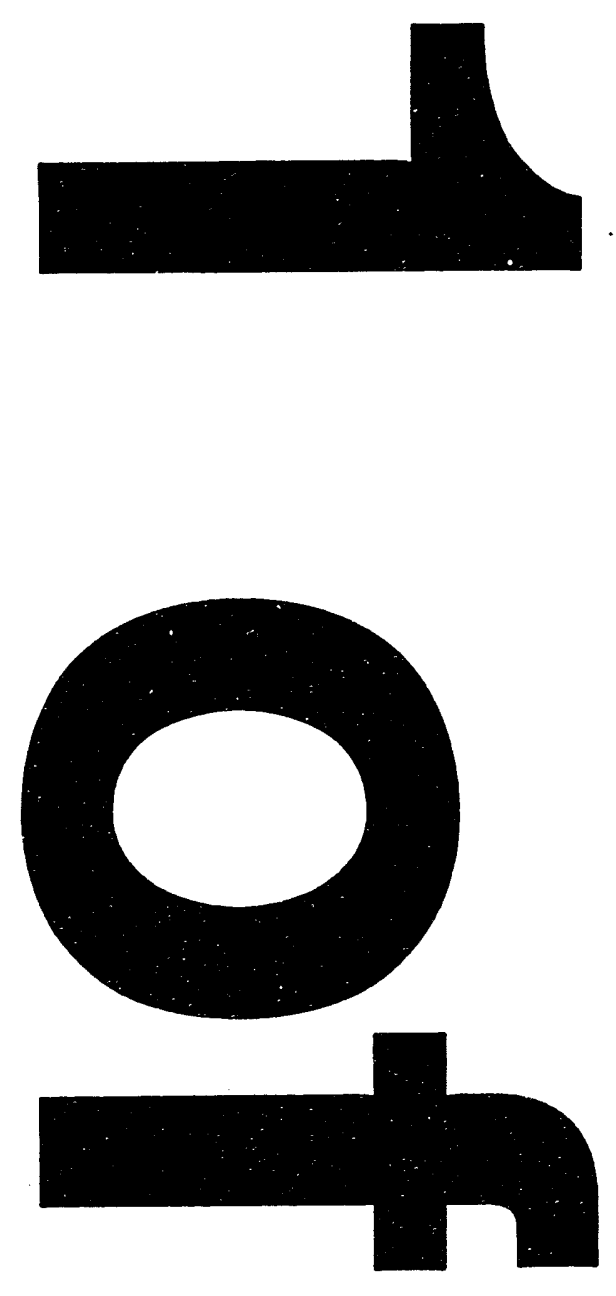

1

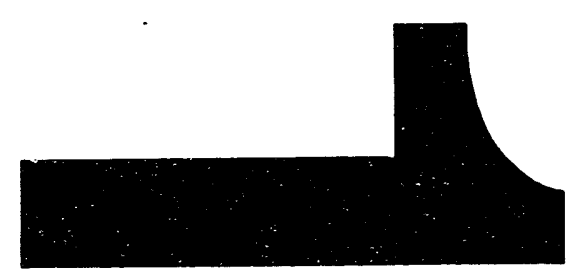




$$
\begin{aligned}
& \text { ANL/TD/CP- }-82439 \\
& \text { Conf-940664--8 }
\end{aligned}
$$

ARGONNE NATIONAL LABORATORY

9700 South Cass Avenue, Argonne, Illinois 60439

\section{Status of Beryllium Development for Fusion Applications*}

by

Michael C. Billone

Fusion Power Program

Energy Technology and Technology Development Divisions

Argonne National Laboratories, Argonne, IL 60439

M. Dalle Donne

KfK Institut für Neutronphysik und Reaktortechnik

P.O. Box 3640, D-76021, Karlsruhe, Germany

R. G. Macaulay-Newcombe

Dept. of Engineering Physics, McMaster University

Hamilton, Ontario, Canada L8S 4L7

Distribution:

D. R. Diercks

I. Gomes

C. E. Johnson

R. F. Mattas

S. Majumdar

D. L. Smith

Beryllium Panel

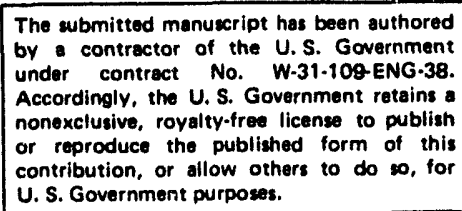

The submitted manuscript has been authored by contractor of the U.S. Government under contract No. W-31-109ENG-38. Accordingly, the U.S. Government retains : nonexclusive, royalty-free license to publish or reproduce the published form of this cor reproduco tho pubstor U. S. Government purposes.

\section{May 1994}

To be presented at the Third International Symposium on Fusion Nuclear Technology, University of California at Los Angeles, June 27-July 1, 1994.

*Work supported in part by the Office of Fusion Energy, U.S. Department of Energy, under contract W-31-109-Eng-38. 


\title{
Status of Beryllium Development for Fusion Applications*
}

\author{
by \\ M. C. Billone \\ Fusion Power Program \\ Energy Technology and Technology Development Divisions \\ Argonne National Laboratory \\ Argonne, IL 60439 \\ M. Dalle Donne \\ KfK Institut für Neutronphysik und Reaktortechnik \\ P.O. Box 3640, D-76021, Karlsruhe, Germany \\ R. G. Macaulay-Newcombe \\ Dept. of Engineering Physics, McMaster University \\ Hamilton, Ontario, Canada L8S 4L7
}

\begin{abstract}
Beryllium is a leading candidate material for the neutron multiplier of tritium breeding blankets and the plasma facing component of first wall and divertor systems. Depending on the application, the fabrication methods proposed include hot-pressing, hot-isostatic-pressing, cold isostatic pressing/sintering, rotary electrode processing and plasma spraying. Product forms include blocks, tubes, pebbles, tiles and coatings. While, in general, beryllium is not a leading structural material candidate, its mechanical performance, as well its performance with regard to sputtering, heat transport, tritium retention/release, helium-induced swelling and chemical compatibility, is an important consideration in first-wall/blanket design. Differential expansion within the beryllium causes internal stresses which may result in cracking, thereby affecting the heat transport and barrier performance of the material. Overall deformation can result in loading of neighboring structural material. Thus, in assessing the performance of beryllium for fusion applications, it is important to have a good database in all of these performance areas, as well as a set of properties correlations and models for the purpose of interpolation/extrapolation.
\end{abstract}


In this current work, the range of anticipated fusion operating conditions is reviewed. The thermal, mechanical, chemical compatibility, tritium retention/ release, and helium retention/swelling databases are then reviewed for fabrication methods and fusion operating conditions of interest. Properties correlations and uncertainty ranges are also discussed. In the case of the more complex phenomena of tritium retention/release and helium-induced swelling, fundamental mechanisms and models are reviewed in more detail. Areas in which additional data are needed are highlighted, along with some trends which suggest ways of optimizing the performance of beryllium for fusion applications.

\section{DISCLAIMER}

This report was prepared as an account of work sponsored by an agency of the United States Government. Neither the United States Government nor any agency thereof, nor any of their employees, makes any warranty, express or implied, or assumes any legal liability or responsibility for the accuracy, completeness, or usefulness of any information, apparatus, product, or process disclosed, or represents that its use would not infringe privately owned rights. Reference herein to any specific commercial product, process, or service by trade name, trademark, manufacturer, or otherwise does not necessarily constitute or imply its endorsement, recommendation, or favoring by the United States Government or any agency thereof. The views and opinions of authors expressed herein do not necessarily state or reflect those of the United States Government or any agency thereof.

* Work supported in part by the U.S. Department of Energy, Office of Fusion Energy, under Contract Number W-31-109-Eng-38. 


\section{INTRODUCTION}

Beryllium has been used as a plasma-facing material in the UNITOR [1], ISX-B [2] and JET [3] tokamak fusion test facilities. It is also under consideration for a variety of applications in conceptual design studies. With regard to first-wall, divertor, and limiter applications, beryllium is the leading candidate for the plasmafacing material, and it has also been evaluated as a possible heat-sink and/or structural material (e.g., ITER/EDA [4]). Most tritium breeding blanket designs call for the use of a neutron multiplier to achieve tritium breeding ratios $\geq 1$. Again, beryllium is the leading neutron-multiplier candidate material. It has also been evaluated as a thermal-resistance layer between the coolant and the solid breeder (e.g., ITER/CDA [5]).

A variety of fabrication methods and as-fabricated shapes have been used for beryllium. The fabrication techniques include vacuum hot pressing (HP), hot isostatic pressing (HIP), cold-isostatic-pressing (CIP)/sintering (S), casting, hot/cold extrusion, ingot metallurgy, rotary electrode processing and plasma spraying. Impurity content, porosity, grain size and texture -- and hence performance -- of the final product vary considerably with fabrication technique. Most techniques start with a beryllium powder. Powder types include S-200-E (< $2.0 \mathrm{wt} . \% \mathrm{BeO}$ ) which was used in early fission reactor applications, S-200-F $(<1.5$ wt.\% Be) used in more recent fission reactor applications and S-65 (<1.0 wt.\% $\mathrm{BeO}$ ) which is currently under consideration for fusion applications. In general, isotropy, ductility and strength improve as the grain size is reduced, while ductility improves as the $\mathrm{BeO}$ content is reduced. As-fabricated shapes for fusion applications include solid rods, annular cylinders, blocks, pebbles, tiles and coatings. 
Plasma-facing and first-wall materials will be subjected to peak surface heat fluxes of about $0.5 \mathrm{MW} / \mathrm{m}^{2}$ for a tokamak operating at a nominal neutron wall loading of $1 \mathrm{MW} / \mathrm{m}^{2}$. Bulk heating rates, damage rates and helium and hydrogenisotope production rates are highly design dependent as most of the total flux of neutrons seen by the $\mathrm{Be}$ is due to back-scattered neutrons from the firstwall/blanket region. The following ranges of values for $\mathrm{Be}$ include those for steel/water or He/ceramic-breeder designs and vanadium-alloy/liquid-Li designs. Bulk heating rates for metallic materials (e.g., 316SS, HT9, V-alloys, Cu alloys, $\mathrm{Be}$ ) at the outboard midplane range from 5-25 MW/m 3 (per $\mathrm{MW} / \mathrm{m}^{2}$ neutron wall loading), with Be and $\mathrm{V}$-alloys at the lower end. The displacement damage rate in Be $\left[4-6 \mathrm{dpa} /\left(\mathrm{MW} \cdot \mathrm{a} / \mathrm{m}^{2}\right]\right.$ is $<50 \%$ of the rate for the other metals. Helium production $\left[3000-6000 \mathrm{appm} /\left(\mathrm{MW} \cdot \mathrm{a} / \mathrm{m}^{2}\right)\right]$ in $\mathrm{Be}$ is considerably higher than in the other metals $\left[60-170 \mathrm{appm} /\left(\mathrm{MW} \cdot \mathrm{a} / \mathrm{m}^{2}\right)\right]$, while protium production is very low compared to the $240-600 \mathrm{appm} /\left(\mathrm{MW} \cdot \mathrm{a} / \mathrm{m}^{2}\right)$ for the other metals. The tritium production in $\mathrm{Be}\left[55-75 \mathrm{appm} /\left(\mathrm{MW} \cdot \mathrm{a} / \mathrm{m}^{2}\right)\right]$ is relatively high due to the presence of the ${ }^{6} \mathrm{Li}$ transmutation product. Thus, two important issues for $\mathrm{Be}$ as compared to other metallic materials are the effects of the high He generation on its geometrical stability and thermal-mechanical properties and the tritium retention/release properties. In terms of the temperature range of interest for design applications, the melting temperature of $\mathrm{Be}$ is $1283^{\circ} \mathrm{C}$. Thermal sublimation of $\mathrm{Be}$ becomes a design issue for $\mathrm{T}>900^{\circ} \mathrm{C}$. Enhanced He-induced swelling and chemical incompatibility with some breeder ceramics and coolants have thresholds in the temperature range of $600-750^{\circ} \mathrm{C}$. Chemical/metallurgical interaction with structural materials is an important consideration for $\mathrm{T}>500^{\circ} \mathrm{C}$. 
In this current work, the properties database for unirradiated and irradiated $\mathrm{Be}$ is reviewed with emphasis on the physical, thermal, mechanical, chemicalcompatibility, helium retention/release and swelling, and tritium retention/release performance parameters. As the behavior of helium and tritium in $\mathrm{Be}$ is both important and quite complicated, the physical mechanisms involved are discussed in some detail, followed by a summary of the progress made in modeling these mechanisms. Emphasis is placed on characterizing the performance parameters for $\mathrm{HP}, \mathrm{HIP}, \mathrm{CIP} / \mathrm{S}$, and plasma-sprayed $\mathrm{Be}$ as functions of as-fabricated porosity and neutron exposure within the temperature ranges of design interest.

\section{DATABASE SUMMARY}

Billone et al. [6] have provided a detailed description of the database for HP and CIP/S Be. They have also developed material properties correlations which can be used by designers to perform thermal, mechanical, compatibility, swelling and tritium retention/release analyses. However, some of the material in Ref. [6] needs to be updated based on more recent data and on new interpretations of old data. Also, the focus of Ref. [6] is on the use of $\mathrm{Be}$ as a blanket multiplier material, rather than as a plasma-facing component. As plasma-spraying of $\mathrm{Be}$ onto $\mathrm{Be}$ tiles is receiving serious consideration for in-situ repair of sputtered tiles, the properties

of plasma-sprayed Be need to be included in the update. The material presented in the following relies heavily on the detailed database presented in Ref. [6]. Primary references are only given for data not included in Ref. [6].

\subsection{Thermal/Physical Properties}


Beryllium has a hexagonal close-packed (HLP) crystalline structure with a theoretical density of $1.85 \mathrm{~g} / \mathrm{cm}^{3}$ and an atom density of $1.24 \times 10^{29}$ atoms $/ \mathrm{m}$. Its melting point is $1556 \mathrm{~K}$ and the heat of melting is $1303 \mathrm{~J} / \mathrm{g}$. The vapor pressure ( $\mathrm{P}_{\mathrm{Be}}$ in $\mathrm{Pa}$ from 1173 to $\left.1556 \mathrm{~K}\right)$, heat capacity $\left(\mathrm{C}_{\mathrm{p}}\right.$ in $\mathrm{J} / \mathrm{g} \cdot \mathrm{K}$ from 300 to $1556 \mathrm{~K}$ ) and thermal conductivity $\left(\mathrm{k}_{\mathrm{o}}\right.$ in $\mathrm{W} / \mathrm{m} \cdot \mathrm{K}$ from $\left.300-823 \mathrm{~K}\right)$ are well established functions of temperature ( $\mathrm{T}$ in $\mathrm{K})$ :

$$
\begin{aligned}
& \log \left(\mathrm{P}_{\mathrm{Be}}\right)=11.192+1.454 \times 10^{-4} \mathrm{~T}-1.6734 \times 10^{4} \mathrm{~T}^{-1} \\
& \mathrm{C}_{\mathrm{p}}=2.432+6.378 \times 10^{-4} \mathrm{~T}-7.11 \times 10^{4} \mathrm{~T}^{-2} \\
& \mathrm{k}_{\mathrm{o}}=291\left(1-1.650 \times 10^{-3} \mathrm{~T}+1.464 \times 10^{-6} \mathrm{~T}^{-2}-5.125 \times 10^{-10} \mathrm{~T}^{3}\right)
\end{aligned}
$$

Small levels of impurities and displacement damage (above $300 \mathrm{~K}$ ) appear to have little effect on the thermal conductivity of Be. However, the presence of asfabricated porosity and/or helium bubbles due to irradiation can cause a large reduction in the effective thermal conductivity $\left(k_{\text {eff }}\right)$ of this material. While there is no universal law for the degradation in conductivity with porosity volume fraction (p) because of the wide variations in pore size, shape and distribution, the following gives a reasonable fit to the data for $\mathrm{HP}$ and foam $\mathrm{Be}$ :

$$
k_{\text {eff }}=(1-p)\left(1+3.7 p^{2}\right)^{-1} k_{o}
$$

The agreement between Eq. 3a and the data for HP Be and low density foam $\mathrm{Be}$ is relatively good for porosities of $0-50 \%$. It is an upper bound for foam Be at $>50 \%$ porosity and a lower bound to data for wire mesh $\mathrm{Be}$ at $80 \%$ volume fraction. However, plasma-sprayed $\mathrm{Be}[7,8]$ is generally highly anisotropic with poor 
thermal conductivity across the thickness direction due to microcracks and the degree of layering of the microstructure. Castro et al [7] report techniques for increasing the density and the effective conductivity of plasma-sprayed Be. Roomtemperature values as high as $70 \mathrm{~W} / \mathrm{m} \bullet \mathrm{K}$ have been realized for $95 \%$ dense plasmasprayed Be, which is $40 \%$ of the value predicted by Eqs. 3, 3a. Higher values have been achieved for post-spray heat-treated $\mathrm{Be}$.

Pebble beds of $\mathrm{Be}$ and $\mathrm{Be} / \mathrm{ceramic}$ will have even lower effective thermal conductivities than pressed or plasma-sprayed Be of equivalent porosity volume fraction. For $2-\mathrm{mm}$ diameter Be pebbles with packing fractions of $58-63 \%$, the measured effective conductivities in atmospheric He range from 2 to $6 \mathrm{~W} / \mathrm{m} \cdot \mathrm{K}$ for $300<\mathrm{T}<865 \mathrm{~K}[9,10]$. The results are sensitive to the external load (either applied or due to differential thermal expansion between the bed and the container) and, to some extent, the roughness of the pebbles. The conductivity can be enhanced by factors of $1.45-1.65$ by the addition of finer size ceramic breeder and/or Be which increases the net packing density up to $\sim 81 \%$ [10].

The thermal expansion $\left(\Delta \mathrm{L} / \mathrm{L}_{\mathrm{o}}\right.$ in \% relative to $\left.298 \mathrm{~K}\right)$ of $100 \%$ dense $\mathrm{Be}$ is less than that for austenitic steels (e.g. $316 \mathrm{SS}$ ) and copper alloys (e.g., $\mathrm{Cu}-\mathrm{Cr}-\mathrm{Zr}-$ $\mathrm{Mg}$ ) and greater than that for martensitic/ferritic steels (e.g., HT9) and vanadium alloys (e.g., $\mathrm{V}-4 \mathrm{Cr}-4 \mathrm{Ti}$ ). In the temperature range of $298-1500 \mathrm{~K}$, it is given by:

$$
\Delta \mathrm{L} / \mathrm{L}_{\mathrm{o}}=8.43 \times 10^{-4}\left(1+1.36 \times 10^{-3}-3.53 \times 10^{-7} \mathrm{~T}^{2}\right)(\mathrm{T}-298)
$$

\subsection{Mechanical Properties}


In general, the mechanical properties of beryllium are highly dependent on the fabrication technique, and hence on the resulting impurity (particularly $\mathrm{BeO}$ ) content and distribution, the effective grain size, orientation and resulting texture, and the porosity fraction, shape and distribution. Irradiation also has a significant effect on the Be mechanical properties. With so much data available on the various types of as-fabricated beryllium, this section is limited to the properties of pressed beryllium: HP, HIP, CIP/S beryllium with either the nuclear grade powder (S$200-F)$ or the better-performing S-65 powder $[11,12]$. Plasma-sprayed Be is also described $[13,14]$.

The Young's modulus ( $\mathrm{E}$ in $\mathrm{GPa}$ ) and Poisson's ratio for Be are relatively independent of impurity level, grain size, and irradiation damage. Poisson's ratio is low $(0.07 \pm 0.06)$ and independent of temperature and porosity. Young's modulus for a wide variety of as-fabricated $\mathrm{Be}$ with $\mathrm{p}<0.3$ and $\mathrm{T}<1050 \mathrm{~K}$ can be represented within $\pm 15 \%$ by:

$$
E=300 \exp (-4.574 p)\left[1-2.016 \times 10^{-4}(T-293)\right]
$$

The temperature dependence of Eq. 5 is based on dynamic tests. Values in the literature based on low strain rate tensile tests which show strong dependence on $\mathrm{BeO}$ content, grain size, and strain rate for $\mathrm{T}>773 \mathrm{~K}$ are deceiving in that nonelastic deformation mechanisms properties (e.g., creep) interfere with the determination of Young's modulus from stress-strain data.

The ultimate tensile strength (UTS in $\mathrm{MPa}$ ) of unirradiated $\mathrm{Be}$ varies significantly with $\mathrm{BeO}$ content, grain size, porosity, and temperature. For S-200 
grade pressed Be with $\mathrm{p}<0.3$ and $293 \leq \mathrm{T}<1273 \mathrm{~K}$, the UTS can be represented by the following correlation within $\pm 10 \%$ as:

$$
\begin{aligned}
\mathrm{UTS}=324 \exp (-4.733 \mathrm{p})[1 & -1.925 \times 10^{-4}(\mathrm{~T}-293)-1.750 \times 10^{-6}(\mathrm{~T}-293)^{2} \\
& \left.+9.198 \times 10^{-10}(\mathrm{~T}-293)^{3}\right]
\end{aligned}
$$

The UTS values for dense S-65 Be are higher by $\sim 30 \%$ at room temperature and about the same as for S-200 Be at T $>673 \mathrm{~K}$. Plasma-sprayed Be with $0.05<\mathrm{p}<$ 0.20 and no post-spray heat treatment, exhibits significantly lower UTS values both in the direction of the spray $\left(0^{\circ}\right)$ and perpendicular to the spray direction $\left(90^{\circ}\right)$. However, by optimizing the starting powder and the post-spray heat treatment leading to densities of $\sim 99 \%$, the UTS can be increased to values even higher than those given by Eq. 6 . While this result may be of general interest, in-situ repair of Be tiles in a fusion reactor by plasma-spraying does not allow certain heat treatments (e.g., HIP and high-temperatures). Finally, irradiation at $\mathrm{T}<873 \mathrm{~K}$ causes hardening of $\mathrm{Be}$ and an increase in UTS to as much as a factor of 4 . Similar behavior has been observed for the ultimate compressive strength (UCS). At low fluences and temperature, the hardening may be due to displacement damage. However, at higher fluences and/or temperature, helium embrittlement is a more likely cause.

The tensile yield strength of dense, unirradiated, pressed $\mathrm{Be}$ is on the order of $250 \mathrm{MPa}$. Similar to the UTS, it decreases significantly with $\mathrm{T}$ and increases with neutron fluence. Porous $\mathrm{Be}$ and/or irradiated $\mathrm{Be}$ are essentially brittle with the yield strength approaching the UTS. The yield strengths in compression and tension are essentially the same. 
The tensile ductility of Be has been studied in great detail. Depending on the details of the fabricition method, the room-temperature ductility of dense, unirradiated, pressed $\mathrm{Be}$ is on the order of $0-6 \%$. For $\mathrm{HP} \mathrm{S}-200-\mathrm{F} \mathrm{Be}$, the room-temperature ductility is only $1.2 \pm 0.3 \%$. It is even lower $(0.6 \pm 0.1 \%)$ for some CIP/S Be with the same starting powder. Using a variety of CIP, S, and HIP techniques and combinations with S-200 grade powders leads to a higher ductility $(2.5 \pm 1.7 \%)$. For $S-65$ starting powder, the ductility is $\sim 5 \%$ under these conditions. Plasma-sprayed $\mathrm{Be}$ has a very low ductility $(\sim 0.2 \%)$ unless it is subjected to post-spray heat treatment. While unirradiated, pressed Be shows ductilities in the range of $10-50 \%$ for $473<\mathrm{T}<873 \mathrm{~K}$, the tensile ductility of irradiated $\mathrm{Be}$ tends to be $\sim 0.2 \%$ in this same temperature range. The irradiation data set does not include the lower BeO-content S-65 Be which has a higher unirradiated ductility than the S-200 series Be. With regard to the effects of asfabricated porosity in the range of 0 to 0.3 , there is a well-characterized decrease in tensile ductility of $\mathrm{HP}$ and CIP/S Be with $\mathrm{p}$ at room temperature: $(1.2 \pm 0.3) \%$ $\exp (-8.0 \mathrm{p})$. Very little data are available on the variation of tensile ductility of porous Be with temperature and/or irradiation. However, $100 \%$ dense Be has near zero ductility after irradiation to fluences of $1 \times 10^{25} \mathrm{n} / \mathrm{m}^{2}(\mathrm{E}>1 \mathrm{MeV})$ in the temperature range of interest, and porous $\mathrm{Be}$ is at least as brittle.

As with all of the non-elastic properties, the thermal creep rate $\left(\dot{\varepsilon}_{c}^{\text {th }}\right.$ in s $\left.{ }^{-1}\right)$ of $\mathrm{Be}$ is highly sensitive to impurities and microstructure. The thermal creep rate of HP S-200-F has been characterized for dense Be for $14 \leq \sigma \leq 21 \mathrm{MPa}$ and $673 \leq$ $\mathrm{T} \leq 973 \mathrm{~K}$ as:

$$
\dot{\varepsilon}_{\mathrm{c}}^{\text {th }}=0.751\left(1-\mathrm{p}^{2 / 3}\right)^{-3.6} \exp \left(-2.60 \times 10^{4} / \mathrm{T}\right) \sigma^{3.6}
$$


where $\sigma$ is the von Mises stress in MPa. The athermal, irradiation creep rate $\left(\dot{\varepsilon}_{\mathrm{c}}^{i}\right.$ in $\mathrm{s}^{-1}$ )has been estimated (based on only one data point for dense $\mathrm{Be}$ at $316 \mathrm{~K}$ ) to be:

$$
\dot{\varepsilon}_{\mathrm{c}}^{\mathrm{i}}=3.2 \times 10^{-6}\left(1-\mathrm{p}^{2 / 3}\right)^{-1} \dot{\mathrm{D}} \sigma
$$

where $\dot{D}$ is the neutron damage rate in dpa/s. Clearly, more irradiation creep data are needed. Also, the thermal creep behavior of each grade of $\mathrm{Be}$ needs to be characterized based on the existing database.

\subsection{Compatibility}

Beryllium has a high affinity for oxygen and, like aluminum, tends to form a protective oxide layer which decreases inter-diffusion and chemical-interaction rates. It is reasonably compatible with air, water, and steam for $\mathrm{T}<600^{\circ} \mathrm{C}$. However, excessive, exothermic interactions with steam have been observed for dense $\mathrm{Be}$ at $\mathrm{T}>800^{\circ} \mathrm{C}$ and for porous $\mathrm{Be}$ at $\mathrm{T}>675^{\circ} \mathrm{C}$. Chemical interaction between $\mathrm{Be}$ layers and lithium-based ceramics initiates at $\sim 700^{\circ} \mathrm{C}$ [15]. For Be spheres in contact with ternary ceramic spheres, chemical interaction layers and diffusion zones have been observed to form on the $\mathrm{Be}$ in the temperature range of $750-950^{\circ} \mathrm{C}$ [16]. Similar behavior has been observed for $\mathrm{Be} / \mathrm{Li}_{2} \mathrm{O}$ at $750^{\circ} \mathrm{C}$. However, at $950^{\circ} \mathrm{C}, \mathrm{Be}$ and $\mathrm{Li}_{2} \mathrm{O}$ pebbles fuse together forming a mixture of $\mathrm{Li}_{2} \mathrm{Be}_{2} \mathrm{O}_{3}, \mathrm{BeO}, \mathrm{Be}$ and $\mathrm{Li}$. Interaction between $\mathrm{Be}$ and austenitic and ferritic structural materials has been characterized. $\mathrm{Be}$ is more reactive with these materials than are the lithium-based ceramics. Both a chemical interaction layer and diffusion zones within each material have been observed. With regard to stainless steel, the following design correlation has been developed to bound the interaction/diffusion 
layer ( $\mathrm{d}$ in $\mu \mathrm{m}$ ) in the steel as a function of time ( $\mathrm{t}$ in hours) based on data at 1003000 hours and 823-1173 K:

$$
d=6.58 \times 10^{4} \exp \left(-1.29 \times 10^{4} / T\right) t
$$

\subsection{He-Induced Swelling}

The high rate of helium generation in $\mathrm{Be}$, along with the high retention fraction, make He-induced swelling an important design issue. A large database is available to describe the low-temperature $\left(<100^{\circ} \mathrm{C}\right)$ swelling of $\mathrm{HP} \mathrm{Be}$. A more limited database is available for the post-irradiation swelling of these samples at annealing times and temperatures of $1-24$ hours and $200-800^{\circ} \mathrm{C}$, respectively. With the exception of the EBR-II database at low He generation (1000 - 2000 appm) and $430-490^{\circ} \mathrm{C}$, swelling has not been well characterized for Be irradiated at temperatures $>100^{\circ} \mathrm{C}$. Also, most data are expressed as swelling vs. fast $(\mathrm{E}>1$ $\mathrm{MeV}$ ) neutron fluence for thermal, mixed, and fast fission neutron spectra. Because fusion spectra are quite different from fission spectra and because of the importance of $\mathrm{He}$ to $\mathrm{Be}$ swelling, it is more useful to correlate the swelling with $\mathrm{He}$ content. Although calculated conversion factors [in appm (He)/1022 $n(E>1$ $\mathrm{MeV}) / \mathrm{cm}^{2}$ ] for thermal and mixed reactors are in the range of 3000-4000, measured values are in the range of $5000 \pm 200$. A design correlation has been developed for volumetric swelling $\left(\Delta \mathrm{V} / \mathrm{V}_{\mathrm{o}}\right.$ in \%) vs. T and He content ( $\mathrm{G}$ in $10^{3}$ appm):

$$
\Delta \mathrm{V} / \mathrm{V}_{\mathrm{o}}=0.115 \mathrm{G}\left[1+3.0 \times 10^{-3} \mathrm{G}^{0.5} \mathrm{~T}^{1.5} \exp (-3940 / \mathrm{T})\right]
$$


Equation 9 agrees quite well ( $\pm 0.34 \%$ strain) with the low temperature irradiation database and the post-irradiation annealing database. However, it does not include rate dependencies, He bubble distributions and as-fabricated parameters (e.g., grain size, porosity, and impurities) thought to be important in determining swelling. Also, the limited database for high temperature, in-reactor swelling tends to exhibit higher swelling rates than does the post-irradiation annealing data and consequently Eq. 9. Clearly, more fundamental modelilng is needed. Important mechanisms for He behavior are discussed in Section 3. Sophisticated models for predicting swelling are discussed in Section 4.

\subsection{Tritium Retention/Release}

Beryllium as a multiplier material generates only $\sim 1 / 100$ of the tritium that the breeder generates. However, if it retains all of this tritium, then $\mathrm{kg}$-levels could build up in the blanket Be by the end of life. Early data on HP Be highly irradiated at low temperature indicated very little post-irradiation annealing release for $\mathrm{T} \leq$ $500^{\circ} \mathrm{C}$, even after 500 hours, and a burst release after several hours at $\sim 600^{\circ} \mathrm{C}$. From a safety viewpoint, this is a highly undesirable situation. However, more recent results for CIP/S Be suggest that the as-fabricated porosity level, as well as the He content, has a strong influence on tritium behavior. The complete data set suggests that tritium is essentially "trapped" in Be below some temperature $T_{0}$ (300 $-500{ }^{\circ} \mathrm{C}$ for dense $\mathrm{Be}$ depending on the He content). Between $\mathrm{T}_{\mathrm{o}}$ and an upper temperature $\mathrm{T}_{b}\left(500-900{ }^{\circ} \mathrm{C}\right.$ for dense $\mathrm{Be}$, again depending on the He content) some of the tritium is released. At and above $T_{b}$, the tritium is released in a burst mode after several hours at temperature. For porous Be ( $\sim 80 \%$ dense), $\sim 25 \%$ of the tritium was released during the low temperature irradiation and a gradual release was observed at each annealing temperature level with only a very small burst of the 
remaining tritium observed at $600{ }^{\circ} \mathrm{C}$. Such behavion is too complicated to describe by a single engineering correlation. Also, the retention/release of tritium for irradiation in the temperature range of interest may be quite different from what is observed for low-temperature-irradiated Be subjected to post-irradiation annealing. Mechanisms for tritium retention and release are discussed in Section 3, while models for predicting tritium behavior are presented in Section 4.

\section{PHYSICAL BASIS OF HELIUM AND TRITIUM RETENTION AND RELEASE BEHAVIOR}

In most materials, helium and tritium are transported or dissolved as interstitials [17]. The very high atomic densities of $\mathrm{Be}$ and $\mathrm{BeO}\left(1.235 \times 10^{29}\right.$ and $1.45 \times 10^{29} \mathrm{at} / \mathrm{m}^{3}$ ) make interstitial tritium and helium energetically unfavorable. For this reason the solubilities and diffusivities should be, and are, very low. In $\mathrm{Be}$, defects and impurities may dominate; in $\mathrm{BeO}$, this would apply to helium, but the chemical effect of the oxygen should dominate the diffusion and dissolution of tritium.

\subsection{Tritium (and Deuterium) in $\mathrm{Be}$ and $\mathrm{BeO}$}

There is a great deal of uncertainty in the values of the solubilities and diffusivities of tritium in $\mathrm{Be}$. (The lesser amount of controversy about $\mathrm{BeO}$ may be due, in part, to its limited database.) The values determined for the diffusivity in $\mathrm{Be}$ at $700 \mathrm{~K}$ range from $10^{-19} \mathrm{~m}^{2} / \mathrm{s}$ to $10^{-10} \mathrm{~m}^{2} / \mathrm{s}$, with activation energies ranging from $0.04 \mathrm{eV}$ to $2.5 \mathrm{eV}$. There is considerable debate as to whether tritium release is dominated by diffusion in the $\mathrm{Be}$, permeation through surface $\mathrm{BeO}$, or recombination at the surface. 
Figure 1 summarizes the hydrogen isotope diffusivity data for $\mathrm{Be}[17,18,20]$ and $\mathrm{BeO}$ [28], as well as for several other metals. Be is hexagonal-close-packed (HCP) with an atomic density of 12.4 (times $10^{28}$ atoms $/ \mathrm{m}^{3}$ ); $\alpha-\mathrm{Ti}$ and $\alpha-\mathrm{Zr}$ are also $\mathrm{HCP}$, with atom densities of 5.71 and 4.30 , respectively; $\mathrm{Ni}$ and $\mathrm{Cu}$, which exhibit nearly identical values for hydrogen diffusivity, are face-centered cubic (FCC), with atom densities of 9.13 and 8.49 , respectively. The effective activation energies for hydrogen isotope diffusion in the metals is in the range of $0.36-0.60$ $\mathrm{eV}$, except for single-crystal $\mathrm{Be}$ which appears to have an activation energy of $\sim 1.1$ eV.

Wampler [18] has conducted careful experiments in an attempt to bypass the surface oxide effect in single crystal Be implanted with helium and deuterium ions. His conclusions, which may apply only to single crystals, were that the oxide is irrelevant, and that the diffusivity and/or solubility in $\mathrm{Be}$ are much lower than the currently accepted values, such as those of Abramov et al. [19] and Swansiger [23]. All the work with polycrystal line Be, such as that found in Ref. $[19,20,23$ 27] seems to indicate that oxide effects are important, and that when the oxide effects are accounted for, the effective diffusivity of tritium in $\mathrm{Be}$ is quite high, 10$12-10^{-10} \mathrm{~m}^{2} / \mathrm{s}$ at $700-900 \mathrm{~K}$. Recent work on single crystal Be [28] indicates that both viewpoints may be correct: the effective solubility seems to be greater than the accepted values $[23,26]$, but the diffusivity in single crystal Be much less than the value determined by, for example, Abramov et al. [19]. With the lower diffusivity in single crystal $\mathrm{Be}$, the permeation barrier effect of the surface oxide would be much less important. There is also evidence that irradiated $\mathrm{BeO}$ has a much higher effective tritium diffusivity than unirradiated $\mathrm{BeO}$ [29]. 
The explanation for the apparent discrepancy between single-crystal and polycrystalline behavior could be that short-circuit grain-boundary diffusion accounts for the difference, as suggested by Maienschein et al. [30]. Note that Maienschein et al. use the same process to account for diffusion measurements in $\mathrm{Al}, \mathrm{Mo}$, and $\mathrm{W}$ metals with much lower atomic densities where this effect might be expected to be less dominant than in Be. Hence, the low activation energy estimates for the diffusivity of tritium in polycrystalline $\mathrm{Be}$ can be attributed to short-circuit diffusion, and the high activation energy estimates can be attributed to surface (and possibly grain boundary) BeO. The base diffusivity of tritium within a grain of Be should be closer to the value derived from Wampler's [18] work.

In $\mathrm{BeO}$, the reference work on tritium diffusivity is that of Fowler et al. [21]. They observed a fairly wide range of diffusivities in studies of sintered $\mathrm{BeO}$, single crystals, and powders, with activation energies ranging from $0.7 \mathrm{eV}-2.3 \mathrm{eV}$. The value for sintered $\mathrm{BeO}, 7 \times 10^{-6} \mathrm{~m}^{2} / \mathrm{s} \exp (-2.1 \mathrm{eV} / \mathrm{kT})$, is generally used for $\mathrm{BeO}$ on Be surfaces. (This is roughly $10^{4}$ times greater than the earlier work of Palmer et al. [31] on $\mathrm{BeO}$ powder.)

The only published estimate of the solubility of hydrogen isotopes in $\mathrm{BeO}$ is that for deuterium in sintered $\mathrm{BeO}$, by Macaulay-Newcombe and Thompson [25]. Their value of $S \cong 10^{18}$ atoms ${ }^{-3}{ }^{-3} \mathrm{~Pa}^{-0.5} \exp (0.8 \mathrm{eV} / \mathrm{kT})$ is based on nuclear reaction analysis measurements of deuterium thermally loaded into $\mathrm{BeO}$, and TMAP [32] calculations matched to thermal desorption spectra. They make a distinction between the bulk solubility and surface layer trapping. The bulk solubility seems to be related to the formation of hydroxide bonds, because of the similarity of the activation energy, $-0.8 \mathrm{eV}$, to the $\mathrm{O}-\mathrm{H}$ bond formation energy of $-0.78 \mathrm{eV}$. However, surface layer deuterium concentrations have been repeatedly measured at 
levels 10-100 times greater than the bulk solubility. These surface layer concentrations vary across the sample surface, which may indicate a sensitivity of the trapping efficiency to the physical nature of the surface corrosion layer, as well as to its chemical composition.

\subsection{Helium in Be and BeO}

There are no published measurements of the solubility of helium in Be and $\mathrm{BeO}$. It seems to be assumed that the solubility is essentially zero. Estimates of the diffusivity include: Jung's [33] value for Be of $2.3 \times 10^{-13} \mathrm{~m}^{2} / \mathrm{s} \exp (-0.6 \mathrm{eV})$; and Gmelin's [34] value for $\mathrm{BeO}, 2.5 \times 10^{-7} \mathrm{~m}^{2} / \mathrm{s} \exp (-3.45 \mathrm{eV} / \mathrm{kT})$. Jung noted a dependence on the helium concentration. It is generally assumed that helium diffuses in $\mathrm{Be}$ and $\mathrm{BeO}$ by some vacancy-assisted mechanism. Another possibility, which seems to produce overestimates of the helium diff ssivity, is to relate $D_{H e}$ to the self-diffusion coefficient, $D_{S D}$. Two similar estimates of $D_{S D}$ in Be are those of Dupouy et al. [35], $5.2 \times 10^{-5} \mathrm{~m}^{2} / \mathrm{s} \exp (-1.63 \mathrm{eV} / \mathrm{kT})$, and Lee et al. [36], $1.9 \times$ $10^{-5} \mathrm{~m}^{2} / \mathrm{s} \exp (-1.67 \mathrm{eV} / \mathrm{kT})$. In BeO, Debriun and Watson [37] estimated $\mathrm{D}_{\mathrm{SD}}$ for the $\mathrm{Be}$ in unirradiated $\mathrm{BeO}$ as $2.5 \times 10^{-7} \mathrm{~m}^{2} / \mathrm{s} \exp (-2.7 \mathrm{eV} / \mathrm{kT})$. Other data in the review by Austerman [38] suggest values up to $10^{3}$ times greater in irradiated $\mathrm{BeO}$.

Tritium release experiments by Baldwin and Billone [20], and by Roux et al. [39] on neutron irradiated Be show that the temperature of irradiation and the density of the Be are both important factors affecting the retention and release of tritium and helium. As might be expected, the higher the temperature of irradiation and the higher the Be porosity, the less tritium and helium are retained in the Be.

\subsection{Trapping of Hydrogen and Helium}


Wampler [40] estimated trap energies (in Be implanted with deuterium at 300 $\mathrm{K})$ of 1.0 and $1.8 \mathrm{eV}$. Anderl et al. [27] found that trap energies in the range of 1.5-1.8 eV could be used to fit their ( $753 \mathrm{~K})$ deuterium ion-driven permeation data. Wampler suggested a saturation value of $5-10$ at $\%$ for the $1.8 \mathrm{eV}$ traps, whereas Anderl et al. indicated a saturation level of about 1 at $\%$ for $1.8 \mathrm{eV}$ traps. The differences may be due to the much higher fluxes and fluences used by Anderl et al., which resulted in the implanted surface being pocked with craters and bubbles, and which sputtered off oxide as quickly as it grew.

Behrisch et al. [29] observed different levels of deuterium retention for implantation into $\mathrm{BeO}$ at 143,298 , and $473 \mathrm{~K}$. They concluded that there was considerable defect-enhanced diffusion. The saturation level at $473 \mathrm{~K}$ was 0.24 $\mathrm{D} / \mathrm{BeO}$, or 14 at\%, suggesting traps of energy $\geq 1.8 \mathrm{eV}$.

Zakaria et al. [41] have studied the trapping of helium in Be by ionimplantation followed by thermal desorption. They concluded that in temperatureramping experiments, the temperature of release was determined by trap energies: $2.3 \mathrm{eV}, 3.0 \mathrm{eV}$, and $>3.0 \mathrm{eV}$, which were attributed to trapping at small vacancy clusters, single vacancies and (possibly) micro-bubbles, respectively. Zakaria et al. noted two other results: (1) a thick ( $28 \mathrm{~nm}) \mathrm{BeO}$ surface oxide delayed release, i.e., it acted as a permeation barrier; and (2) the desorption spectra changed after aging at $\mathrm{T} \leq 300 \mathrm{~K}$, indicating considerable defect-enhanced diffusion. No published data on He trapping in $\mathrm{BeO}$ have been found.

Evidence exists in the literature $[18,20,39]$ that helium in beryllium acts as a trapping site for tritium. There is some indication that the interaction of implanted 
(trapped) helium and thermally loaded deuterium causes release of helium (and/or deuterium) at lower temperatures than when one or the other is loaded on its own [42].

\subsection{Surface Adsorption and Desorption}

Lossev and Küppers [43] have measured adsorption and desorption of deuterium on clean and oxidized $\mathrm{Be}<0001>$ surfaces. They found that $\mathrm{BeO}$ covered surfaces released all adsorbed deuterium by $\sim 450 \mathrm{~K}$, with an activation energy for release of $0.6 \mathrm{eV}$. In contrast, clean Be surfaces showed a release activation energy of $0.9 \mathrm{eV}$, and desorption was not complete until the temperature was $>600 \mathrm{~K}$. Above about $400 \mathrm{~K}$, absorption into the bulk and diffusion within the bulk began to complicate the analysis. The sticking coefficient for coverage of $\theta<0.1$ was estimated as $0.8-1.0$ for clean $\mathrm{Be}$ and $0.4-0.5$ for $\mathrm{BeO}$. The saturation coverage was $\theta \cong 0.5$.

\subsection{Surface Recombination Coefficients}

The value of the surface recombination coefficient, $K_{r}$, appears to be highly dependent on the surface condition. Hsu et al [44] reported that deuterium release from JET Be tiles was dominated by recombination, with a strong oxide effect. They compared their results to others and found that estimates of $K_{r}$ varied over 8 orders of magnitude. Converting their units from $\mathrm{D} / \mathrm{K}_{\mathrm{r}}$ to $\mathrm{K}_{\mathrm{r}}$ using their estimate of

$D\left(10^{-13} \mathrm{~m}^{2} / \mathrm{s}\right)$ results in $\mathrm{K}_{\mathrm{r}} \sim 10^{-27}-10^{35} \mathrm{~m}^{4} / \mathrm{s}$. Whether or not recombination will dominate tritium release in a fusion reactor may depend very much upon ti.e surface composition, the tritium concentration and temperature, as discussed at more length by Macaulay-Newcombe et al. [45]. Another important factor will be the local 
surface area, determined by the porosity of the Be. This will determine the effective thickness of the Be layer. Under reactor conditions this effective thickness will change as the surface is eroded and roughened by ion-impact and bubble formation.

\section{STATUS OF MODELING OF SWELLING AND TRITIUM RELEASE IN IRRADIATED BERYLLIUM}

Although the modeling of gas retention/release and swelling for fission reactors fuels has received a great deal of attention, relatively little progress has been made in modeling tritium and helium behavior in beryllium. Recently, a mechanistic code capable of predicting the performance of beryllium in the blanket of a fusion reactor up to high neutron fluences has been developed at KfKKarlsruhe. A code, previously written at the Institute for Transuranium Elements in Karlsruhe for analyzing the behavior of fuel pellets in fission reactors [46], was modified to model the relevant processes which are thought to affect gas behavior and swelling in beryllium.

\subsection{Computer Model Description}

The computer code ANFIBE (ANalysis of Fusion Irradiated BEryllium) describes the gas kinetics and dynamics and the helium-induced swelling in beryllium. The relevant effects occurring in irradiated beryllium under stationary or transient temperature conditions have been considered on a microscopic (lattice and subgranular volume elements), structural (metallographic features of the material) and geometrical (specimen design parameters) point of view. The beryllium specimen is ideally considered as an arrangement of spherical grains in which helium, generated by the reaction of fast neutrons with beryllium, migrates to the 
free surfaces and/or precipitates into intragranular bubbles. These can also migrate (at a much lower rate than the free atoms) through the grains to the grain boundaries to form grain-face and grain-edge bubbles (intergranular bubbles) usually larger than the intragranular ones. Bubbles may grow by capture of gas and coalesce to create larger bubbles with a lower restraint capillarity pressure. The growth of intragranular and intergranular bubbles causes a plastic deformation of the lattice resulting in material swelling. For relatively large volume increases, grain-face and grain-edge bubbles can become interlinked and merge into an open porosity network through which the gas can escape from the specimen. The modeling of the interlinkage of intergranular pores and bubbles is based on percolation theory [47].

The developed mathematical model is expressed by a system of seven reaction-rate differential equations which describe the helium short- and long-range transport. Each term in the equations represents a source or loss term of the respective concentration due to a distinct mechanism. A more detailed discussion of their expression is given in [48]. The seven differential equations are integrated by using the three bubble radii (intragranular, grain-face and grain-edge) calculated from additional expansion equations resulting from the interplay of all forces (i.e., gas pressure, capillarity stresses, internal stresses, etc.) acting on the intragranular, grain-face and grain edge bubbles respectively.

The model used to describe the behavior of tritium is formally identical to that of helium. The only important difference is due to an additional rate-equation accounting for the chemical trapping of the tritium by oxygen impurities.

Schematically, the tritium behavior is described as follows: once it has been generated it can diffuse in the lattice, or be captured by physical traps (such as 
intragranular helium bubbles, closed porosity, grain boundaries, etc. as in the case of helium), or it may react with beryllium oxide to form beryllium hydroxide by the chemical reaction:

$$
2 \mathrm{BeO}(\mathrm{cr}, \beta)+2 \mathrm{H}(\mathrm{g}) \rightarrow \mathrm{Be}(\mathrm{OH})_{2}(\mathrm{cr}, \beta)+\mathrm{Be}(\mathrm{cr})
$$

the STP formation enthalpy of which is about $-0.8 \mathrm{eV}$. The tritium concentration may be calculated from an Arrhenius type relation (van't Hoff's equation) where the pre-exponential argument is represented by the free energy of formation for the above chemical reaction.

In the code development a major part of the work consisted in reformulating the constitutive relations used in the equations and selecting the parameters specific to beryllium, the most important of which are the surface tension over solid beryllium, the beryllium self-diffusion coefficient, the bubble diffusion coefficient, the beryllium thermal creep rate and, for the tritium release model, the tritium diffusivity in beryllium.

\subsection{Validation of the Computer Model}

\subsubsection{Beryllium swelling}

A comparison of the calculated swelling with in-pile experimental data for a wide range of irradiation conditions (i.e., irradiation temperatures from $50^{\circ} \mathrm{C}$ to $700^{\circ} \mathrm{C}$, neutron fluences from $2.1 \times 10^{21} \mathrm{n} / \mathrm{cm}^{2}\left(E_{n}>1 \mathrm{MeV}\right)$ to $5.0 \times 10^{22} \mathrm{n} / \mathrm{cm}^{2}$ $\left(E_{n}>1 \mathrm{MeV}\right)$ and helium contents from $1155 \mathrm{appm}$ to $\left.26100 \mathrm{appm}\right)$ is shown in Fig. 2. The agreement between the ANFIBE predictions and experiments is 
excellent. The experimental data cover independently the ranges of temperatures, fast neutron fluences and helium contents for the European DEMO blankets. However, more data are required to qualify ANFIBE especially from experiments in which irradiations to high fluences have been carried out at high temperatures, on the effects of $\mathrm{BeO}$ content and distribution on the helium diffusivity, and of $\mathrm{BeO}$ and other impurities on the surface tension over solid beryllium and on the creep rate. Indeed, it appears necessary to assume values of helium diffusivity, of surface tension and of creep rate different from those used for western modern hot pressed beryllium to model the swelling data from Russian experiments related to relatively old beryllium [49].

\subsubsection{Tritium release}

Data on tritium release are available from the post-irradiation annealing results of Baldwin and Billone (for both moderately irradiated $81 \%$ and $97 \%$ dense and highly irradiated $100 \%$ dense beryllium) [20], and from the SIBELIUS experiment for a low-irradiated $98 \%$ dense beryllium [50,51].

The agreement between model prediction and experiment for low and moderately irradiated dense beryllium is good [48,52]. However, the ANFIBE code is not yet suited to model porous beryllium. Furthermore, although the tritium release is well predicted at temperatures $\geq 500^{\circ} \mathrm{C}$, at lower temperatures the code underpredicts the tritium release from the highly irradiated dense beryllium, see Fig. 3 [48]. This fact, which may be attributed to the formation of microcracks in the beryllium due to the rapid temperature change during the out-of-pile annealing, has also been found for out-of-pile tritium release experiments for beryllium irradiated at high fluences in the BR2 reactor in Mol [53]. Of course, highly irradiated 
beryllium is more likely to crack under thermal stresses as it is more brittle. ANFIBE does not yet account for the effect of the microcracks.

It is quite clear that ANFIBE requires further development. Also, more extensive experimental data are required, especially from experiments in which irradiations at high fluences have been carried out at high temperatures. In-pile tritium release experiments would also be highly desirable.

\section{DISCUSSION}

While the database for unirradiated and irradiated $\mathrm{Be}$ is extensive, there are also a large number of fabrication variables involved. With regard to fusion applications, it is important to characterize the properties and evaluate the database for each type of fabricated beryllium in order to select the Be with the best combination of thermal, mechanical, chemical-compatibility, tritium release and helium swelling performance The most complete data set is for HP and CIP/S S200-F nuclear grade Be because of its application in fission reactors. Based on unirradiated properties, it appears that S-65 Be has higher strength and ductility. However, little is known about the irradiation performance of this material, in particular its ductility vs. dpa and He content, swelling and tritium release characteristics. If the ductility of irradiated S-65 Be is also poor, then it is likely that the embrittlement problem will be resolved, at least in a design sense, by the use of small (e.g., pebbles) pieces of $\mathrm{Be}$ in the blanket.

Most of the swelling and tritium release data are from post-irradiation annealing experiments. These data appear insufficient to resolve the more relevant issue of the behavior of $\mathrm{Be}$ irradiated at temperatures of design interest. Also, for 
modeling purposes better characterization of the as-fabricated distribution of porosity and $\mathrm{BeO}$ impurity is needed, as well as the bubble morphology for irradiated Be. Reducing the $\mathrm{BeO}$ impurity level and the grain size appears to be desirable with regard to improving unirradiated mechanical properties, but little is known about the effects of such reduction on tritium release, helium-induced swelling, and irradiated mechanical properties. Iircreasing as-fabricated porosity improves the tritium release and may decrease the swelling rate, but it also introduces compatibility problems (e.g., Be/steam). During the ITER/CDA phase, the U.S. irradiated a number of porous and dense Be specimens in FFTF at designrelevant temperatures. Inspection of these samples would increase the swelling and mechanical properties database considerably. Similar irradiations currently being conducted in EBR-II are scheduled for completion in August 1994. Recently, Be irradiations involving S-65 and S-200 Be at $200-600^{\circ} \mathrm{C}$ were completed in the BR-2 reactor as part of a European collaborative effort [54]. The results of these tests will answer many of the remaining questions about $\mathrm{Be}$ performance. However, with the pulse mode of operation anticipated for the next generation of fusion devices, the fatigue and fracture toughness properties of irradiated $\mathrm{Be}$, which have received relatively little attention in the past, wi!l become more important. Finally, irradiation creep, which may act as a stress-reliever in $\mathrm{Be}$ at low temperatures needs to be better characterized.

At temperatures $<800 \mathrm{~K}$, irradiated beryllium can be expected to retain as much as 0.1 at. \% tritium or more, depending on its structure and BeO level. Helium retention will probably be greater than tritium retention. This could be a problem if a temperature excursion caused plasma-facing Be to heat up above 900 K. The problem could be intensified for Be with a high degree of interconnected porosity and therefore a large surface area. One option to counteract this is to try to 
maximize the trapping of $\mathrm{He}$ and tritium by using high-density Be with the addition of impurities in such a way as to pin helium micro-bubbles. This would minimize bubble growth and delay the release of tritium and helium during temperature excursions. Furthermore, high-density $\mathrm{Be}$ acts as a tritium permeation barrier, whereas Be with $>5 \%$ porosity is highly permeable.

Significant progress has been made over the past several years in modeling the behavior of tritium and $\mathrm{He}$ in irradiated $\mathrm{Be}$. The modeling needs to be expanded to include the effects of as-fabricated porosity. Also, data on bubble size distributions and locations, as well as overall swelling data on Be irradiated at temperatures of design interest, would be very valuable for improving the models and validating the ANFIBE computer code, which has been developed for this application.

\section{CONCLUSIONS}

Beryllium is a leading candidate as a plasma-facing and neutron multiplier for fusion reactors. While the database for $\mathrm{Be}$ is quite extensive, much of it is for the low-ductility nuclear grade of hot-pressed Be used in fission reactors. Major improvements have been made in fabricating $\mathrm{Be}$ with lower $\mathrm{BeO}$ content and higher unirradiated ultimate tensile strength and ductility. However, the performance of this newer Be under irradiation has yet to be determined. Upcoming data from a European irradiation test program which has recently been completed will help to resolve some of these issues. Also, the athermal irradiation-induced creep and the fatigue and fracture-toughness properties of irradiated $\mathrm{Be}$ need to be better characterized. 
With regard to tritium and helium behavior in irradiated $\mathrm{Be}$, significant progress has been made in generating postirradiation annealing data on tritium retention/release and in modeling the behavior of tritium and helium. However, data are needed - for model development/validation purposes, as well as for direct design application - on the tritium retention/release, helium retention/release, $\mathrm{He}$ bubble size distribution, irradiated microstructure, and swelling of $\mathrm{Be}$ irradiated at temperatures of design interest. Irradiated samples are available for this purpose from the European program and the U.S.ITER R\&D program.

In selecting the optimum fabrication method, and hence microstructure and impurity content/distribution, for $\mathrm{Be}$ to be used in fusion applications, the thermal, mechanical, chemical compatibility, tritium retention/release, and He-induced swelling performances need to be considered. Although the overall database for $\mathrm{Be}$ is quite extensive and inclusive of a wide variation in fabrication parameters, more complete data sets are needed for a limited number of promising fabrication techniques. Some of these data will be provided by analysis of already-completed irradiation experiments. Additional experiments should be planned which include the nuclear grade S-200-F Be as a reference, the better-performing S-65 Be, and plasma-sprayed (with and without post-spray heat treatment which would be practical for in-situ repair) Be. 


\section{References}

1. J. Hackman and J. Uhlenbusch. Test of a Beryllium Limiter in the Tokamak UNITOR. J. Nucl. Mater. $128 \& 129$ (1984) 418-421.

2. P.H. Edmonds, P. Mioduszewski, J.B. Roberto, R.D. Watson and M.F. Smith. The ISX-JET Beryllium Limiter Experiment. J. Nucl. Mater. 128\&129 (1984) $422-424$.

3. A.P. Martinelli, A.T. Peacock and R. Behrisch. Deuterium Trapping and Impurity Collection on a 1990 JET Be Belt Limiter. J. Nucl. Mater. 196-198 (1992) 729-734.

4. ITER Director. Detail of the ITER Outline Design Report, Fourth Meeting of the Technical Advisory Committee. Report ITER TAC-4-01, San Diego Joint Worksite (January 10-12, 1994).

5. D. Smith, A. Antipenkov, C. Baker, M. Billone, W. Daenner, Y. Gohar, T. Kuroda, P. Lorenzetto, K. Maki, S. Mori, A. Raffray, G. Shatalov, A. Sidorov, G. Simbolotti, I Sviatoslavsky, H. Takatsu and H. Yoshida. ITER: Tritium Breeding Blanket. Proc. IAEA 13th Internat. Conf. on Plasma Physics and Controlled Nuclear Fusion Research, Washington D. C., October 1-6, 1990, Vol. 3.IAEA-CN-53/F-III-11(1991)379-386. 
6. M.C. Billone, W. Dienst, T. Flament, P. Lorenzetto, K. Noda and N. Roux. ITER Solid Breedti Blanket Materials Database. Argonne National Laboratory Report ANL/FPP/TM-263 (Nov. 1993).

7. R.G. Castro, P.W. Stanek, L.W. Jacobson and D.F. Cowgill. The Effect of Processing Parameters on Plasma Sprayed Beryllium for Fusion Applications. in Proc. Workshop on Beryllium for Fusion Applications, Karlsruhe, Germany, r

October 4-5, 1993, ed. M. Dalle Donne, Kernforschungszentrum Karlsruhe Report KfK 5271 (Dec. 1993) 252-276.

8. RD. Watson. Thermal Conductivity of Plasma Sprayed Beryllium. Proc. Beryllium Technology Workshop, Clearwater Beach FL, November 20, 1991, ed. G. R. Longhurst, Idaho National Engineering Laboratory Report EGG-FSP10017 (Dec. 1991), Append. E.

9. F. Tehranian. Effect of External Load on Particle Beds Thermal Properties. University of California at Los Angeles Report UCLA-FNT-68/UCLA-ENG-9324 (May 1993).

10. M. Dalle Donne, A. Goraieb and G. Sordon. Measurements of the Heat Transfer Parameters of Mixed Beds of Beryllium and Lithium Orthosilicate Pebbles. Proc. Workshop on Beryllium for Fusion Applications, Karlsruhe, Germany, October 4-5, 1993, ed. M. Dalle Donne, Kernforschungszentrum Karlsruhe Report KfK, 5271 (Dec. 1993) 172-184.

11. I. Dunmur, N. Davey and T.R. Moules. The Nature of Plasma Sprayed Beryllium and the Effect of Heat Treatment. BERYLLIUM/1977, Proc. 4th 
Internat. Conf. on Beryllium, Royal Society, London (October 4-7, 1977) 35/112.

12. I.W. Dunmur. Plasma-Sprayed Beryllium. in: Beryllium Science and Technology. Vol. 2. ed. D. R. Floyd and J. N. Lowe (Plenum Press, New York, 1979) pp. 135-175.

13. N. Pinto. Properties. in: Beryllium Science and Technology. Vol. 2, ed. D. R. Floyd and J. N. Lowe (Plenum Press, New York, 1979) pp. 319-350.

14. N.R. Borch. Elevated Temperature Behavior. in: Beryllium Science and Technology. Vol. 1. ed. D. Webster and G. J. London (Plenum Press, New York, 1979) pp. 307-330.

15. M. Dalle Donne, G. Kalinin, R. Mattas and S. Mori. Material Problems and Requirements Related to the Development of Fusion Blankets: The Designer Point of View. Presented at ICFRM-6, accepted for publication in J. Nucl. Mater. (1994).

16. Y. Yoshida, M. Enoeda, M. Nagakura, S. Kobayashi and Y. Ozawa. Blanket Materials R\&D from Engineering Aspects of Lithium Ceramic-BerylliumSteel Systems in ITER Blanket. in: Fusion Technology 1992, ed. F. M. Gasparotto and H. Knoepfel (Elsevier Science, 1993) pp. 1547-1551.

17. S.M. Myers, P.M. Richards, W.R. Wampler and F. Besenbacher. Ion-beam Studies of Hydrogen-Metal Interactions. J. Nucl. Mater. 165 (1989) 9-64. 
18. W.R. Wampler. Trapping of Deuterium in Beryllium. J. Nucl. Mater. 196198 (1992) 981-985.

19. E. Abramov, M.P. Riehm, D.A. Thompson and W.W. Smeltzer. Deuterium Permeation and Diffusion in High-Purity Beryllium. J. Nucl. Mater. 175 (1990) 90-95.

20. D.L. Baldwin and M.C. Billone. Diffusion/Desorption of Tritium from Irradiated Beryllium. Presented at ICFRM-6, accepted for publication in J. Nucl. Mater. (1994).

21. J.D. Fowler, D. Chandra, T.S. Elleman, A.W. Payne and K. Verghese. Tritium Diffusion in $\mathrm{Al}_{2} \mathrm{O}_{3}$ and BeO. J. Amer. Ceram. Soc. 60 (1977) 155-161.

22. J. Völkl and G. Alefeld. Hydrogen Diffusion in Metals. in: Diffusion in Solids, ed. A.S. Nowick and J.J. Burton (Academic Press, N.Y., 1975) pp. 233302.

23. W.A. Swansiger. Summary Abstract: Tritium Solubility in High-Purity Beryllium. J. Vac. Sci. Technol. A4 (1986) 1216.

24. H. Kawamura, E. Ishituka, N. Sakamoto and H. Sagawa. Be Research Activities for In-Pile Test. JAERI Report (October 11, 1991).

25. R.G. Macaulay-Newcombe and D.A. Thompson. The Effects of Surface Contamination on Absorption and Desorption of Deuterium in $\mathrm{Be}$ and $\mathrm{BeO}$. Presented at ICFRM-6, accepted for publication in J. Nucl. Mater. (1994). 
26. P.M.S. Jones and R. Gibson. Hydrogen in Beryllium. J. Nucl. Mater. 21 (1967) 353-354.

27. R.A. Anderl, M.R. Hankins, G.R. Longhurst, R.J. Pawelko and R.G. Macaulay-Newcombe. Hydrogen Transport Behavior of Beryllium. J. Nucl. Mater. 196-198 (1992) 986.

28. R.G. Macaulay-Newcombe, private communication.

29. R. Behrisch, R.S. Blewer, J. Borders, R. Langley, J. Roth, B.M.U. Scherzer and R. Schulz. Implantation of $5 \mathrm{keV}$ Dueterium in BeO. Rad Eff. 48 (1980) 221-224.

30. J.L. Maienschein, F.E. McMurphy and V.L. Duval. Increase of Tritiun Permeation Through Resistant Metals at $323 \mathrm{~K}$ by Lattice Defects. Fus. Technol. 14 (1988) 701-706.

31. A.R. Palmer, D. Roman and H.J. Whitfield. The Diffusion of Tritium from Irradiated Beryllium Oxide Powders. J. Nucl. Mater. 14 (1964) 141-146.

32. Tritium Migration Analysis Program, Version 4, developed at EG\&G INEL by G.R. Longhurst, J.L. Jones and B.J. Merrill; EGG-FSP-10315.

33. P. Jung. Diffusion and Retention of Implanted Helium in Beryllium. J. Nucl. Mater. 202 (1993) 210-215. 
34. E. Gmelin. Diffusion et Precipitation de L'Helium dans L'oxyde Beryllium Irradie et Recuit. J. Nucl. Mater. 38 (1971) 150-162.

35. M.-M. Dupouy, J. Mathie and Y. Adda. Autod.ffusion du Beryllium. Mem. Sci. Rev. Met. 63 (1966) 481-487.

36. C.H. Lee, J.B. Drew, G.E. Spangler and M. Herman. Self-diffusion in Beryllium Single Crystals. in: Beryllium Technology, Vol. I, ed. L.M. Schetky and H.A. Johnson (Gordon and Breach, Science Publishers, N.Y., 1966) pp. 307317.

37. H.J. De Bruin, G.M. Watson. Self-Diffusion of Beryllium in Unirradiated Beryllium Oxide. J. Nucl. mater. 14 (1964) 239-247.

38. S.B. Austerman. Self-Diffusion in Beryllium Oxide. J. Nucl. Mater. 14 (1964) 248-257.

39. N. Roux, J.J. Abassin, M. Briec, D. Cruz, T. Flament and I. Schuster. Compatibility Behavior of Beryllium with $\mathrm{LiAlO}_{2}$ and $\mathrm{Li}_{2} \mathrm{ZrO}_{3}$ Ceramics and $316 \mathrm{~L}$ and 1.4914 Steels in SIBELIUS. J. Nucl. Mater. 191-194 (1992) 168-172.

40. W.R. Wampler. Retention and Thermal Release of Deuterium Implanted in Beryllium. J. Nucl. Mater. 122\&123 (1984) 1598-1602.

41. Y.M. Zakaria, R.G. Macaulay-Newcombe and D.A. Thompson. Thermal Desorption of Implanted Helium from Beryllium. Proc. Workshop on Beryllium 
for Fusion Applications, Karlsruhe, October 4-5, 1993, ed. M. Dalle Donne, Kernforschungszentrum Karlsruhe Report KfK 5271 (Dec. 1993) 331-341.

42. R.G. Macaulay-Newcombe, D.A. Thompson and W.W. Smeltzer. Deuterium Diffusion, Trapping and Release in Ion-Implanted Beryllium. Fus. Eng. and Des. 18 (1991) 419-424.

43. V. Lossev and J. Küppers. Interaction of Hydrogen Atoms with Beryllium (0001) Surfaces. J. Nucl. Mater. 196-198 (1992) 953-957.

44. W.L. Hsu, R.A. Causey, B.E. Mills, J. Ehrenberg and V. Phillips. Transient Release of Deuterium from Beryllium after Plasma Ion Implantation. J. Nucl. Mater. 176\&177 (1990) 218-225.

45. R.G. Macaulay-Newcombe, D.A. Thompson and W.W. Smeltzer. Thermal Adsorption and Desorption of Deuterium in Beryllium and Beryllium Oxide. J. Nucl. Mater. 191-194 (1992) 263-267.

46. C. Ronchi and J. van der Laan. The Fuel Performance Code FUTURE. EUR Report 11387 EN (1988).

47. C. Domb and M.S. Green. Phase Transitions and Critical Phenomena. Vol. II (Academic Press, London, 1972) p. 197.

48. M. Dalle Donne, F. Scaffidi-Argentina, C. Ferrero and C. Ronchi. Modeling He-Induced Swelling in Beryllium during Fast Irradiation, and Computer Simulation of Tritium Retention and Release in Irradiated Beryllium. Proc. 
Workshop on Beryllium for Fusion Applications. Kernforschungszentrum Karlsruhe Report, KfK 5271 (1993) pp. 105-119 and 149-163.

49. F. Scaffidi-Argentina and M. Dalle Donne. Private communication, Kernforschungszentrum Karlsruhe (1994).

50. W. Dienst et al. Tritium Release of $\mathrm{Li}_{4} \mathrm{SiO}_{4}, \mathrm{Li}_{2} \mathrm{O}$ and Beryllium and Chemical Compatibility of Beryllium with $\mathrm{Li}_{4} \mathrm{SiO}_{4}$ and Steel (SIBELIUS Irradiation). Kernforschungszentrum Karlsruhe Report, KfK 5109 (1992).

51. L. Dörr, T. Eberle, J. Lebkücher and H. Werle. Long-time Tritium Release from Irradiated Beryllium (SIBELIUS Irradiation). Proc. Workshop on Beryllium for Fusion Applications. ed. M. Dalle Donne, Kernforschungszentrum Karlsruhe Report, KfK 5271 (1993) 138-148.

52. F. Scaffidi-Argentina et al. Helium-induced Swelling and Tritium Trapping Mechanisms in Irradiated Beryllium: A Comprehensive Approach. This conference.

53. H. Werle. Private communication. Kernforschungszentrum Karlsruhe (1994).

54. M. Dalle Donne, L. Anzidei, H, Kwast and F. Moons. Status of EC Solid Breeder Blanket Designs and R\&D for DEMO Fusion Reactors. This conference. 


\section{Figure Captions}

1. Hydrogen isotope diffusivity in single-crystal (SC) and sintered-product (SP) $\mathrm{Be}$ and $\mathrm{BeO}$ and high-atom-density hexagonal-close-packed (HCP) and facecentered-cubic (FCC) metals.

2. Comparison of ANFIBE calculations and experimental swelling data for inpile irradiated beryllium classified according to irradiation temperature [48].

3. Time dependence of fractional tritium release from $99 \%$-dense beryllium [20] as compared to results calculated by ANFIBE [48]. 


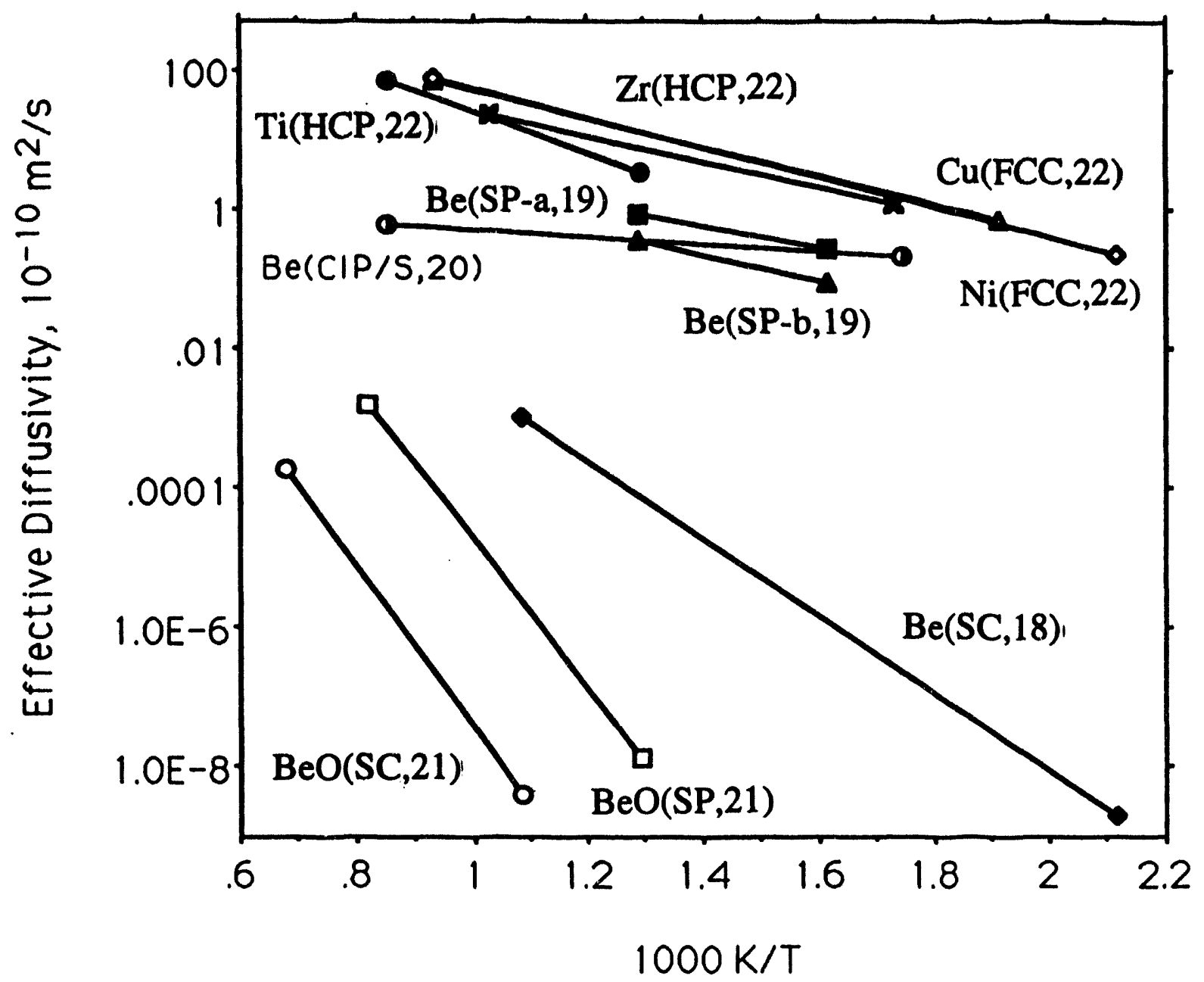

Figure 1

Michael C. Billone et al.

Status of Beryllium Development for Fusion Applications 


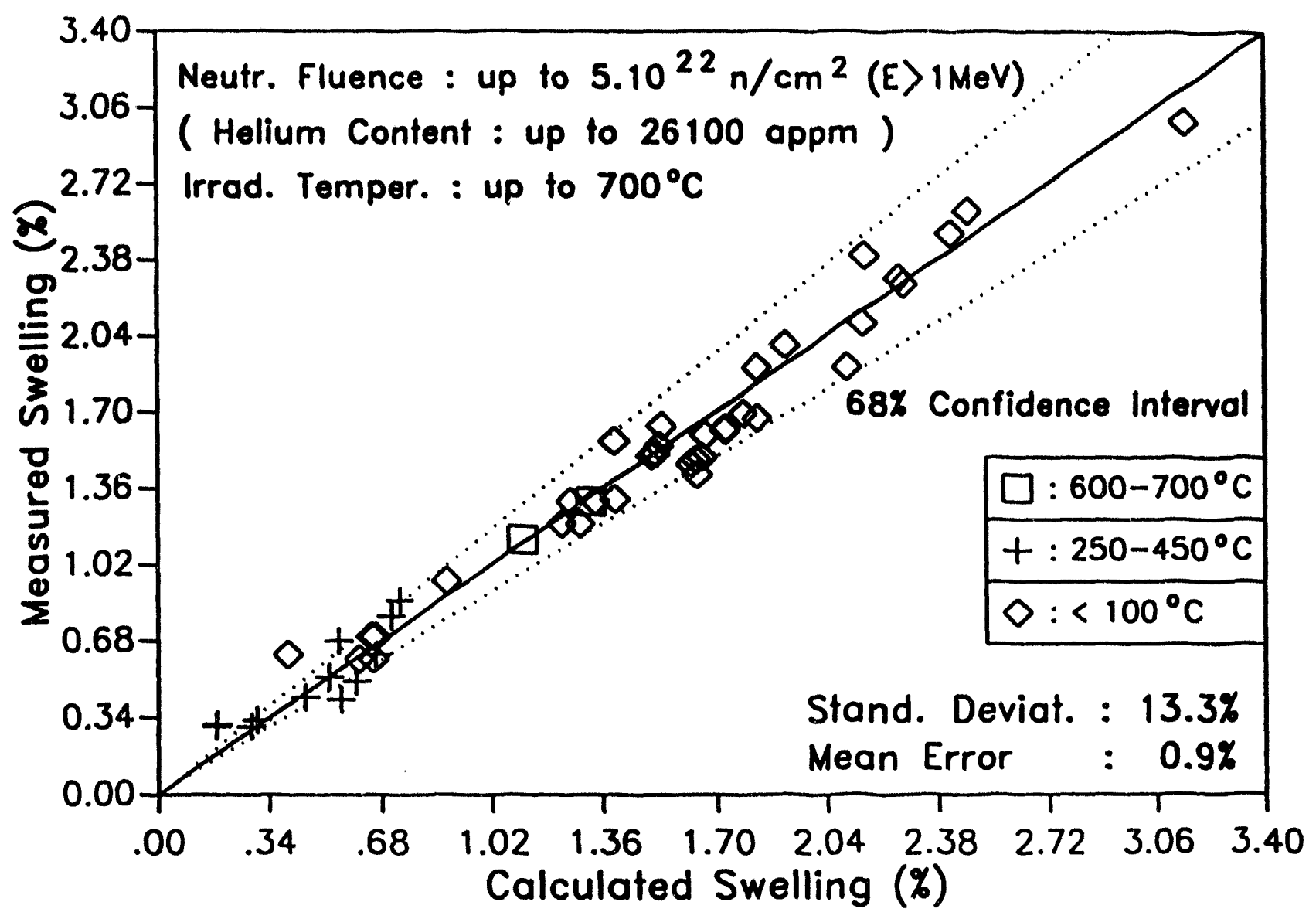

Figure 2

Michael C. Billone et al.

Status of Beryllium Development

for Fusion Applications 


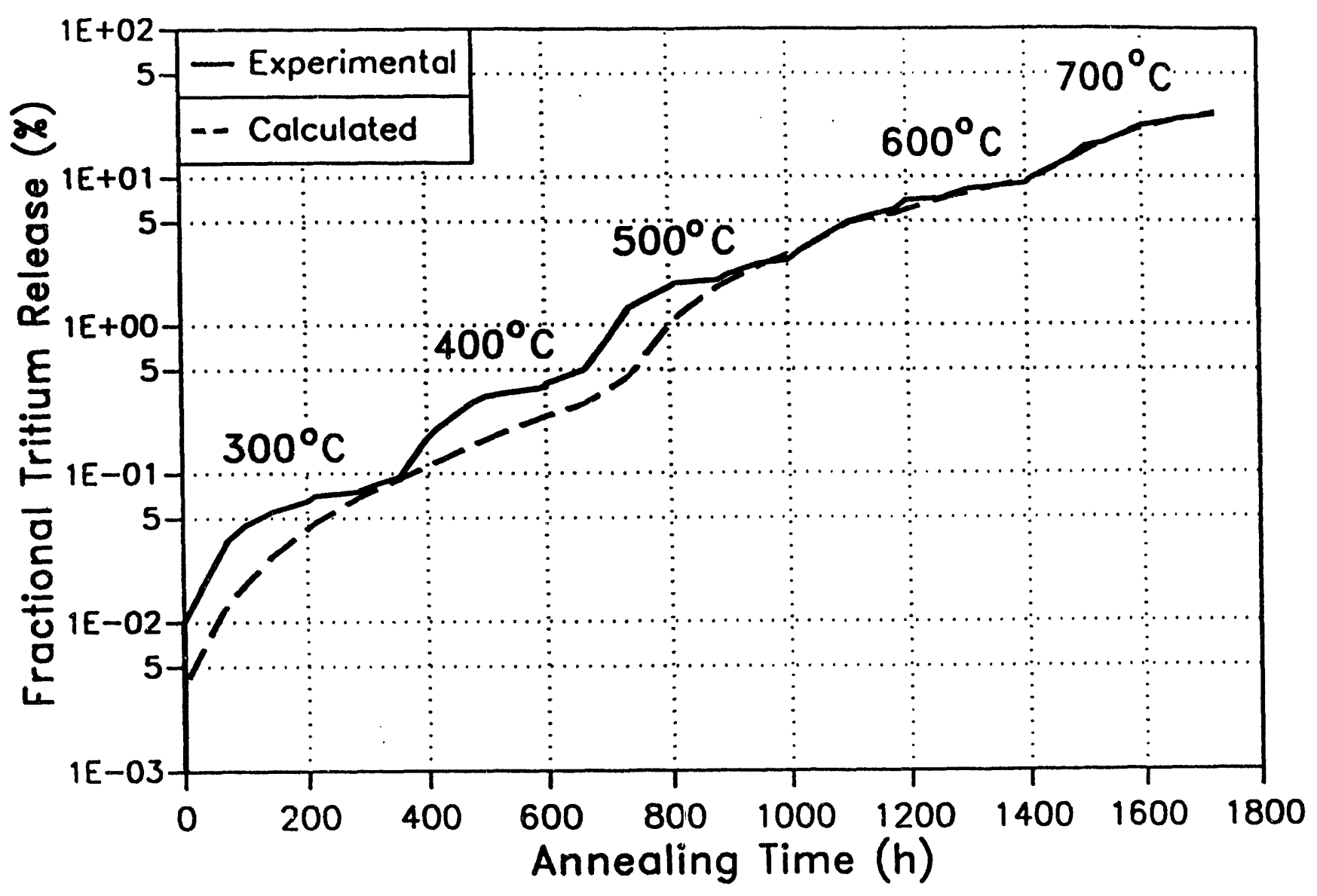

Figure 3

Michael C. Billone et al.

Status of Beryllium Development for Fusion Applications 


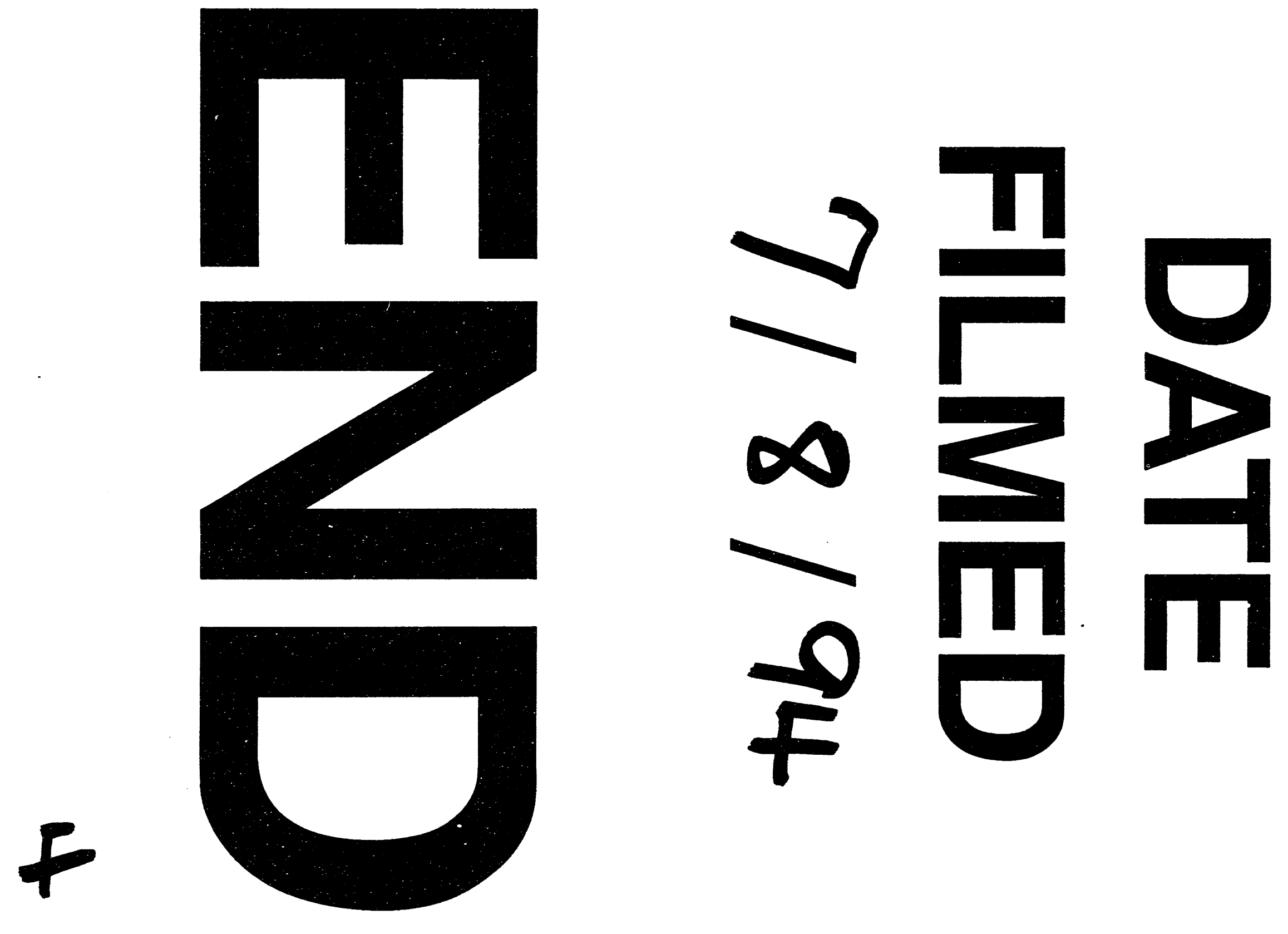


